\title{
"Knowledge and attitudes of Spanish adolescent girls towards human papillomavirus infection: where to intervene to improve vaccination coverage"
}

Pedro Navarro-IIlana ${ }^{1 *}$, Javier Diez-Domingo², Esther Navarro-IIlana', José Tuells ${ }^{4}$, Sara Alemán ${ }^{3}$ and Joan Puig-Barberá ${ }^{3}$

\begin{abstract}
Background: HPV vaccine coverage is far from ideal in Valencia, Spain, and this could be partially related to the low knowledge about the disease and the vaccine, therefore we assessed these, as well as the attitude towards vaccination in adolescent girls, and tried to identify independently associated factors that could potentially be modified by an intervention in order to increase vaccine coverage.

Methods: A cross sectional study was conducted in a random selection of schools of the Spanish region of Valencia. We asked mothers of 1278 girls, who should have been vaccinated in the 2011 campaign, for informed consent. Those that accepted their daughters' participation, a questionnaire regarding the Knowledge of HPV infection and vaccine was passed to the girls in the school.

Results: 833 mothers (65.1\%) accepted participation. All their daughters' responded the questionnaire. Of those, 89.9\% had heard about HPV and they associated it to cervical cancer. Only 14\% related it to other problems like genital warts. The knowledge score of the girls who had heard about HPV was 6.1/10. Knowledge was unrelated to the number of contacts with the health system (Pediatrician or nurse), and positively correlated with the discussions with classmates about the vaccine. Adolescents Spanish in origin or with an older sister vaccinated, had higher punctuation. $67 \%$ of the girls thought that the vaccine prevented cancer, and $22.6 \%$ felt that although prevented cancer the vaccine had important safety problems. $6.4 \%$ of the girls rejected the vaccine for safety problems or for not considering themselves at risk of infection. $71.5 \%$ of the girls had received at least one vaccine dose. Vaccinated girls scored higher knowledge $(p=0.05)$.
\end{abstract}

Conclusion: Knowledge about HPV infection and vaccine was fair in adolescents of Valencia, and is independent to the number of contacts with the health system, it is however correlated to the conversations about the vaccine with their peers and the vaccination status. An action to improve HPV knowledge through health providers might increase vaccine coverage in the adolescents.

Keywords: Vaccines, Papillomavirus infections, Papillomavirus vaccines, Adolescent behavior, Health knowledge, Attitudes, Practice

\footnotetext{
* Correspondence: pedro.navarro@ucv.es

${ }^{1}$ Facultad de Enfermería, Universidad Católica de Valencia "San Vicente

Mártir", C/Jesús, 10, 46007 Valencia, Spain

Full list of author information is available at the end of the article
} 


\section{Background}

Chronic infection with Human Papillomavirus (HPV) is known to cause a range of pre-cancerous, cancerous and being lesions like genital warts [1]. In Spain, cervical cancer is the sixth most common malignancy, representing $4.8 \%$ of all cancers in women. However its incidence is one of the lowest worldwide (Predicted age standardized rate in 2012 of 11.6 cases per 100.000 women/year) [2] and the mortality rate of 2.7 per 100.000 women/year, similar to European average [3,4].

HPV vaccines are highly efficacious in preventing chronic infections and dysplasias by serotypes 16 and 18, the most common oncogenic types [5-8].

Routine vaccination for all girls aged 14 years is recommended in Valencia, since October 2008, and available free of cost. However, the vaccine coverage decreased since its implementation. In $2008,85 \%$, of the target population received at least one HPV vaccine dose, and $73,9 \%$ received all three doses. The following year coverage dropped to $66.1 \%$ for one and $63.3 \%$ for three doses. Factors that could have influenced were: lack of awareness about the infection, the impact of the media in relation to some alleged safety problems at the beginning of the vaccination program [9], and concerns about vaccine effectiveness promulgated by local critical groups [10].

It is therefore important to develop activities in order to increase the vaccine coverage. As a first step we considered to assess the knowledge about the disease and vaccine and the attitudes towards the vaccine in the target groups, so that could devise interventions directed to the weaker points.

Worldwide many of the studies have examined individual awareness, knowledge and attitudes towards vaccination. Prior to the vaccine licensure, most of the studies reported as most significant a lack of knowledge, and recurrent myths, e.g. the impact of vaccination on promiscuity [11].

Subsequently, large vaccination campaigns in different countries have had a favorable impact on the perception of the vaccine to prevent disease. In the era post vaccine distribution, knowledge was positively associated with older age, higher education, number of sexual partners, previous diagnosis of cervical dysplasia or having ad an HIV test, and it was negatively associated in the United States with Latin American origin, opposition to premarital sex and certain religious beliefs $[12,13]$.

In several studies, summarized in a systematic review there is a correlation between vaccine uptake and HPV disease and vaccine knowledge, attitudes regarding vaccination and having a healthcare provider as a source of information [14]. However [15] there is not strong evidence to recommend any specific educational intervention related to HPV vaccine for wide-spread implementation, as the quality of the trials published so far is low and in literate populations, therefore future studies are required to determine the effectiveness of culturally- competent interventions reaching diverse populations. In the same way, a metanalysis found that individual interventions (not during a health encounter) to inform or educate parents have a low impact on their babies vaccine coverage, although again the information is limited and of low quality, and the main recommendation was to do this communication as a complementary activity in a clinic [16].

There are few studies assessing the knowledge and attitudes of exclusively young adolescents towards vaccination. This age group is important as the primary target population for the vaccine delivery. At this age as girls become more independent, their decision to be or not vaccinated is, at least, as important as their parents' [17]. At this age, less than $5 \%$ of the girls have had their first sexual intercourse [18], and therefore their sexual history, an important driver for higher knowledge, is less relevant.

A recent report from colleges in the United Kingdom, reported a low awareness and knowledge about HPV and HPV vaccination in a cohort of girls that were offered the vaccination through a school-based program [19].

The objective of our study was to assess the knowledge and attitudes of 15 year-old Spanish girls (who were candidates to receive the vaccine) towards HPV infection and the vaccine, and to identify independently associated factors that could potentially be modified by an intervention.

\section{Methods \\ Design}

A cross-sectional descriptive study in adolescent girls (aged 15, born in 1995) was carried out. All data was collected between September 2010 and May 2011. The girls were eligible to receive and complete the HPV vaccine series in the previous season (by June 2010).

Adolescent girls were recruited from primary schools of the Province of Valencia, Spain. Schools were randomly selected depending on the population for each of the Counties of the Province, and included private and public schools.

Both, mothers and girls completed an informed consent forms prior to any research activity. Investigators sent the informed consent to mothers through the school head teachers. The teachers collected the forms. Schools were paid $€ 10$ per each mother's signed informed consent collected.

Adolescents completed the study questionnaire in the school, in the presence of one person from the research team. Prior to distribution all participants received the same information, and no further comments were made after the questionnaire was handed to the girls to avoid biasing the answers.

The Ethics Committee of the Center for Public Health Research (CSISP), Valencia, Spain approved the study. 


\section{Instrument}

A questionnaire, which consisted of 38 items, was developed. It assessed demographic information, social variables, including religious affiliation and religious practice, and social status of the family as recommended by the Spanish Epidemiology Association [20]. Use of health resources included the number of times in the previous year that they had a pediatric, GP, nurse or gynecologist consultation, and whether they were followed up due to any chronic condition. Toxic consumption: smoking, cannabis, cocaine and pills could have been 'never consumed', 'consumed', 'seldom consumed' or 'habitual consumption'. Awareness of social problems was quantified using 5-points Likert scales $(1=$ no concern to 5 = extremely concerned) in 9 questions, including terrorism, epidemics, accidents, school failure and safety. Awareness of health problems was also quantified using the same Likert scales in 9 items, asking for concern about cancer, infectious diseases (i.e. AIDS and STDs), depression, new epidemics, diseases related to alcohol or other drugs and obesity. Two scores were developed, a social awareness score and a health awareness score. Each was calculated as the mean of the punctuation of the individual items (1 to 5).

HPV disease and HPV vaccine awareness were assessed by two items: 'have you ever heard about HPV?' and 'have you ever heard about the HPV vaccine?'.

HPV knowledge was assessed using a 16 closed ended true/false items. By HPV knowledge we are referring to the degree to which a person possesses and understands objective information pertinent to HPV. To discourage guessing by the participants, researchers instructed them to choose 'don't know'. Distracter items, which assessed higher level of understanding of HPV infection, were included. These included an item to rule out the connection between HPV and ovarian cancer. We also included true/ false statements (i.e. HPV produces hepatic cancer), to assess knowledge discrimination through rejection of false statements [21]. A knowledge summary score was computed by assigning one point for each correct response and zero points for each incorrect and 'don't know' answers. Points were summed to create a knowledge summary score.

HPV vaccine knowledge was assessed with five questions: 'How many doses are required for a complete vaccination schedule' and four closed ended true/false items on the effect of the vaccine on future infections, the need to use condoms, the need to follow genital screening and the effect towards cervical cancer.

The means of receiving information about the vaccine was assessed with the question: 'where have you heard about HPV vaccine?'.

Attitudes towards general vaccination were assessed by a Likert scale in two questions asking about their attitudes and their friends', and also two open questions asking about their beliefs regarding benefits and problems of vaccines.

HPV vaccination attitude was assessed by asking the girls' opinion about the vaccine, possible answers were: 'it is a very good vaccine to prevent cervical cancer', 'it is a vaccine that prevents cervical cancer but has problems', 'it is a good vaccine but is painful and I am frightened' and 'it is a vaccine for a disease I will never get'.

We also asked about the sources for vaccine information (e.g., TV, press, radio, internet, brochures/leaflets, pediatrician, nurse, parents and friends). A general summary question asked the girls to consider and select the most relevant statement about the vaccine: it is a very good vaccine to prevent cervical cancer', 'it is a vaccine to prevent cancer but it is problematic', 'it is a good vaccine but I am frightened because it hurts', 'it is a disease I am never getting and therefore I am not receiving the vaccine'. The answer to the number of vaccine doses received was checked with the Valencian vaccine registry, concordance was very high (Kappa $=0.92)$.

The questionnaire was piloted to validate comprehension among 15 girls in one school situated within a socioeconomic deprived area and used to validate the comprehension of the questions.

\section{Statistical analysis}

For qualitative variables, number and percentage with its normal 95\% CI were calculated, with missing data included in the calculation of percentages. Non-parametric or ordinal variables were compared using the MannWhitney-Wilcoxon test when comparing two groups, or the Kruskal-Wallis test when comparing three or more groups. Correlations were estimated between the HPV knowledge summary score and all variables potentially related to knowledge. Pearson Product Moment Correlations were calculated to estimate the relationship between two continuous variables and Point-Biserial correlations were calculated to estimate the relationship between a dichotomous variable (e.g., provider recommendation for the HPV vaccine: yes or no) and a continuous variable (HPV knowledge).

All data processing was performed using SPSS for Windows (Version 15).

\section{Questionnaire validation}

Cronbach's alpha was used to assess internal consistency of each construct of the questionnaire. When the alpha value was lower than 0.70 , we considered that each of the individual questions from these constructs actually measured multiple unrelated psychological domains. Questions from these constructs were considered individually in the multivariate linear regression model of predictors of parental HPV vaccine acceptability. 


\section{Results \\ Sample}

1278 mothers distributed among the schools were asked for informed consent, 833 (65.1\%) accepted participation, in all those cases; their daughters fulfilled the questionnaire in the school and were included in the analysis.

Eighty percent of the adolescents lived with both parents and their socioeconomic status was similar to that occurring in Spain in 2010. Most of the parents (82.5\%, 95\% CI: 79.9-85.1\%) were Spanish in origin and 11.3\% from South America. Over 85\% of the girls were born in Spain (Table 1).

\section{Adolescents' concerns and attitudes towards social and health problems}

Among the social problems that girls were concerned about, school and sport accidents were the least rated, while those more severe or with higher media impact were of highest concern: road traffic accidents and terrorist attacks (Table 2). Concerns about health problems were diverse, being the weight problems the most rated (Table 2), with $78.5 \%$ (95\% CI: 75.7-81.3\%) of the girls being worried about it.

Table 1 Characteristics of the study participants

\begin{tabular}{|c|c|c|}
\hline & $\mathrm{N}$ & $\%$ \\
\hline \multicolumn{3}{|l|}{ Country of birth } \\
\hline Spain & 716 & 86.0 \\
\hline Other & 116 & 14 \\
\hline \multicolumn{3}{|l|}{ Current family status } \\
\hline Living with both parents & 658 & 79.0 \\
\hline Parents divorced/separated & 138 & 16.5 \\
\hline Father or mother widow & 25 & 3.0 \\
\hline Other & 12 & 1.4 \\
\hline \multicolumn{3}{|l|}{ Religious beliefs } \\
\hline Practising & 117 & 0.14 \\
\hline Occasional practising & 133 & 16.0 \\
\hline Non-practising & 303 & 36.4 \\
\hline Non-believer & 215 & 25.8 \\
\hline No answer & 65 & 7.8 \\
\hline Parents occupation & Father (\%) & Mother (\%) \\
\hline Unemployed & $52(6.9)$ & $12(1.6)$ \\
\hline Undergraduate/director $>10$ & $187(24.7)$ & $117(15.5)$ \\
\hline Postgraduate/director $<10$ & $30(4.0)$ & $87(11.5)$ \\
\hline Admin./self-employed & $171(22.6)$ & $100(13.2)$ \\
\hline Qualified technician & $176(23.5)$ & $97(12.8)$ \\
\hline Semi-qualified technician & $38(5.0)$ & $33(4.4)$ \\
\hline Unqualified worker & $100(13.2)$ & $311(41.1)$ \\
\hline
\end{tabular}

Study sample $n=833$.
Table 2 Social and health concerns and toxic consumption among adolescent girls in Spain

\begin{tabular}{lcc}
\hline & $\%$ & $\mathbf{9 5 \% ~ C l}$ \\
\hline Social-health worries* & & \\
Road traffic accidents & 82.8 & $80.2-85.4$ \\
Terrorist attacks & 76.5 & $73.6-79.4$ \\
Weight problems & 59 & $55.7-62.3$ \\
AIDS & 78.5 & $75.7-81.3$ \\
STDs & 73.7 & $70.7-76.7$ \\
Toxic consumption & & \\
TOBACCO & & $42.6-49.8$ \\
$\quad$ Never smoked & 46.0 & $14.6-19.7$ \\
$\quad$ Consumed regularly & 17.2 & $79.6-84.8$ \\
Alcoholic beverages & & $28.3-34.6$ \\
$\quad$ At least once & 82.2 & \\
$\quad$ Consumed regularly & 31.5 & $76.6-82.2$ \\
Cannabis & & $2.6-5.2$ \\
$\quad$ Never tried & 79.4 & Consumed regularly \\
\hline
\end{tabular}

*Percentage of responders that were worried or very worried with the social or health problems.

Tobacco consumption is high among the adolescent girls as $17.2 \%$ (95\% CI: 14.6-19.7\%) consumed it regularly (Table 2). Alcoholic beverages had been drunk, at least once, by $82.2 \%$ (95\% CI: 79.6\%-84.8\%) and cannabis consumed regularly by $3.9 \%$ (95\% CI: $2.6-5.2 \%)$. There was a high linear correlation between tobacco and cannabis consumption $(\mathrm{p}<0.001)$. Tobacco consumption was unrelated to the concerns that girls had about cancer, alcohol or tobacco related diseases, weight problems, AIDS or STDs, as well as school failure or depression.

\section{Knowledge, attitudes and beliefs towards HPV infection and vaccination}

The majority of the study participants (89.9\%) had heard about HPV infection and knew its association to female genital cancer, and all of them associated HPV with cervical cancer; although 39.1\% (95\% CI: 35.8\%-42.4\%) also associated HPV with ovarian cancer. A lower percentage of girls had knowledge about the role of HPV infection among males with 5.5\% (95\% CI: 3.9\%-7.0\%) relating it with penis cancer and $26.9 \%$ (95\% CI: $26.8 \%-33.0 \%$ ) related it to a male infection (Table 3).

Only $14 \%$ (95\% CI: $11.6 \%-16.4 \%$ ) of the girls knew the association between HPV and genital warts.

Most of the girls (86.2\%; 95\% CI: $83.8-88.5 \%)$ of the total sample were aware of the mechanism of transmission of the infection and 61\% (95\% CI: 57.7-64.3\%) did not consider themselves to be at risk of infection.

With regards to potential ways of avoiding the diseases, $83.9 \%$ (95\% CI: 81.4-86.4\%) considered the use of 
Table 3 Knowledge of adolescents in relation to HPV and HPV vaccine $(n=833)$

\begin{tabular}{|c|c|c|c|}
\hline & Yes (\%) & No (\%) & $\begin{array}{c}\text { Don't } \\
\text { know }(\%)\end{array}$ \\
\hline \multicolumn{4}{|l|}{ Diseases related to HPV } \\
\hline Penis cancer & $46(5.5)$ & $628(75.4)$ & $159(19.1)$ \\
\hline Ovarian cancer & $326(39.1)$ & $314(37.7)$ & $193(23.3)$ \\
\hline Genital warts & $117(14.0)$ & $438(52.6)$ & $278(33.4)$ \\
\hline Cervical cancer & $750(90.0)$ & $22(2.6)$ & $61(7.3)$ \\
\hline \multicolumn{4}{|l|}{ Transmission } \\
\hline Lack of hygiene & $29(3.5)$ & $683(82.0)$ & $121(14.5)$ \\
\hline Intimate kissing & $19(2.3)$ & $706(84.8)$ & $108(13.0)$ \\
\hline Transmitted by boys & $224(26.9)$ & $425(51.0)$ & $184(22.1)$ \\
\hline Sexual intercourse & $718(86.2)$ & $26(3.1)$ & $89(10.7)$ \\
\hline \multicolumn{4}{|l|}{ Ways of preventing HPV diseases } \\
\hline Hand washing & $67(8.0)$ & $551(66.1)$ & $214(25.7)$ \\
\hline Good hygiene & $429(51.9)$ & $273(32.8)$ & $130(15.6)$ \\
\hline Condoms & $699(83.9)$ & $45(5.4)$ & $88(10.6)$ \\
\hline Cannot be prevented & $104(12.5)$ & $389(46.7)$ & $338(40.6)$ \\
\hline \multicolumn{4}{|l|}{ HPV vaccine } \\
\hline $\begin{array}{l}\text { If vaccinated I will never } \\
\text { get HPV infection }\end{array}$ & $289(34.7)$ & $539(64.7)$ & $5(0.6)$ \\
\hline $\begin{array}{l}\text { If vaccinated I will not } \\
\text { need condom any longer } \\
\text { in sexual intercourses }\end{array}$ & $10(1.2)$ & $821(98.6)$ & $2(0.2)$ \\
\hline $\begin{array}{l}\text { If vaccinated I will need } \\
\text { cervical cancer screening }\end{array}$ & $789(94.7)$ & $42(5.0)$ & $2(0.2)$ \\
\hline $\begin{array}{l}\text { HPV vaccine completely protects } \\
\text { against cervical cancer }\end{array}$ & $211(25.3)$ & $612(73.5)$ & $10(1.2)$ \\
\hline
\end{tabular}

condoms, $51.9 \%$ thought that an adequate personal hygiene avoided infection, and $12.5 \%$ (95\% CI: $10.2-14.7 \%$ ) considered that HPV infection could not be avoided.

The mean of the knowledge score, in those girls that had heard about HPV before the questionnaire, was 6.1 out of 10. It was positively related to the girl being Spanish in origin $(\mathrm{p}=0.015)$ and having older sisters that had received the HPV vaccine $(\mathrm{p}=0.016)$, and it was unrelated to their religious affiliation or health care attendance.

Most of the girls had heard about the HPV vaccine (97.4\%; 95\% CI: 96.3-98.5\%), although some of them did not know what HPV was. With respect to beliefs and attitudes towards HPV vaccination, 539 (64.7\%; 95\% CI: 61.4$67.9 \%)$ knew that the vaccine potentially protected against any HPV infection and 25\% (95\% CI: 22.1-27.9\%) thought that the vaccine completely protected against cervical cancer.

The utility of condoms, after vaccination, as protective barrier during sexual intercourse was reported by 821 (98.5\%; 95\% CI: 97.7-99.3\%). Of the 833 girls, 789 (94.7\%; 95\% CI: 93.2-96.2\%) thought that, despite vaccination, cervical screening was needed for secondary prevention.

\section{Do girls talk with their peers about the vaccine?}

771 adolescents (92.6\%; 95\% CI: 90.8-94.4\%) had recently spoken with classmates or friends about the vaccine. The most common topic was that the vaccine hurt $(82.4 \%$; $95 \%$ CI: $79.8-84.9 \%)$, it was very reactogenic $(78.3 \%$; $95 \% \mathrm{CI}$ : 75.5-81.1\%) and that it was a source of diseases (71.3\%; $95 \%$ CI: $68.2-74.4 \%)$, but also that it was a very good vaccine to prevent cancers (73.1\%; 9\%CI: 70.1-76.1\%). The overall positive comment among adolescents, that the HPV vaccine was very good, was a matter of discussion in $59.4 \%$ (95\% CI: 56.1-62.7\%) of the cases.

In general, adolescents concurred with the statement that the vaccine was very good for preventing cancers, 558 girls (67\%; 95\% CI: 63.8-70.2\%); $22.6 \%$ (95\% CI: $19.7-$ $25.4 \%$ ) felt that, although it prevented cancer, it had important problems. And 6.4\% (95\% CI: 4.7-8.1\%) of the girls thought that they would definitely not have the vaccine because of the adverse events, and 3.2\% (95\% CI: 2.0-4.4\%) because they were not at risk of infection.

There was a good positive correlation between adolescents discussing the vaccine with their peers and their knowledge score $(\mathrm{p}<0.05)$.

\section{Health system utilization: impact on HPV knowledge and vaccine attitude}

During the previous year, 699 girls (84\%; 95\% CI: 81.5$86.5 \%$ ) had visited their GP or primary care pediatrician, 63\% (95\% CI: 59.7-66.3\%) more than once; 51\% (95\% CI: 47.6-54.4\%) attended a nurse clinic in primary care.

Of the 833 girls of the total sample, $12 \%$ (95\% CI: 9.8$14.2 \%)$ were followed up for chronic conditions, primarily allergies and asthma and, less frequently, scoliosis or migraine.

A small percentage, 7\% (95\% CI: 5.3-8.7\%), acknowledged not having received all the recommended vaccines during childhood or was unaware of their vaccination status.

In general, the adolescent population were positioned positively for vaccination, with only $1 \%(95 \% \mathrm{CI}$ : $0.3-$ $1.7 \%$ ) completely against vaccination, $2.4 \%$ (95\% CI: $1.4-$ $3.4 \%$ ) not being very positive, and $21.0 \%$ (95\% CI: 18.2 $23.8 \%)$ were indifferent towards vaccination with a very strong association between their belief on vaccination and their peers' $(\mathrm{p}<0.001)$.

The number of visits to the GP/pediatrician or nurse was unrelated to the knowledge score, the social and health awareness scores or their beliefs about HPV infection and the vaccine.

Vaccination status: 596 girls had received at least one vaccine dose at the time of the questionnaire $(71,5 \%$; 95\% CI: $68.5-74,6 \%$ ), and scored higher knowledge than non vaccinated (6.02 vs. $5.75 ; \mathrm{p}=0.05)$.

Only other two variables were significantly correlated with HPV knowledge: parents being of Spanish origin and having a sister that had been previously vaccinated. 
These variables were independently associated with the knowledge score and accounted for 5.8 of the variance in HPV knowledge score.

\section{Questionnaire validation}

Internal reliability estimates were calculated for each construct and found to be adequate for the Social awareness, disease awareness and HPV knowledge with a Cronbach's alpha between 0.86 and 0.78 .

\section{Discussion}

This study showed that adolescent girls in Spain had a fair knowledge about HPV infection and its prevention, with still important gaps, to remark the unbalanced perceived safety profile of the vaccine and that many do not consider themselves at risk of infection.

An important finding was the lack of relation between the girls' knowledge and their attendance to the health system, and no correlation with the number of visits to either the pediatrician or the nurse, this meant that either the health provider did not invest time in discussing these facts or the explanation was not understood.

There are studies [22] where health care utilization is a positive predictor for vaccination, however there are areas where the provider recommendations are limited $[23,24]$. In Vadaparampil's survey [24], over half of the pediatricians questioned in the United States had a low knowledge on HPV and perceived vaccine safety as a barrier for vaccination. However this finding was unrelated to their recommendation, as over $75 \%$ of the pediatricians followed the vaccine schedules, and recommended HPV vaccine in most of the visits for this age group of girls.

Unlike the impact of pediatricians or nurses on HPV knowledge, there is a strong correlation with peer discussions. This is an important finding as the information in this age group might come from less accurate sources and without quality filters. A review of Internet sources showed than both German and Spanish websites lacked balanced reporting on the completeness, transparency and exact dimensions of HPV and HPV vaccination [25]. Unbalanced media coverage may fuel vaccine alarm, and be shared among peers without any interaction with health care providers/system and may pose a risk to HPV vaccination programs.

In our study vaccinated girls scored higher in the knowledge construct, however whether higher knowledge was a driver for vaccination or the fact of being vaccinated suppossed higher knowledge (by instance the number of vaccine doses) is unknown. Adolescent and parents' knowledge about HPV and HPV vaccination are frequently associated with vaccine uptake [14,26-28]. Although still not proven, an intervention to promote HPV vaccine knowledge may reduce one of the barriers for HPV vaccination. A recent German trial suggested that balanced information to the parents and girls, through brochures, increased the knowledge about HPV, but did not increase the vaccine uptake when compared to a group not receiving adequate information [29]. However, this last measurement, analyzed one year after the informative period, might be diluted by the mixing of both groups in the same classrooms, where information is shared and discussed. A systematic review that assessed the educational interventions used to increase HPV vaccine acceptance [15] showed that due to the quality of most of the trials and the population targeted, there is no evidence that increasing the knowledge about HPV does not improve vaccination coverage, therefore further studies of higher quality are required.

With the recommendation that vaccine be administered at age 14, young adolescent girls, may consider vaccination as one of their first health related decisions. In fact, although most of the times parents think that vaccinating their adolescent daughters should be their decision [30,31], in some studies parents agreed that a well-informed child should be able to request HPV vaccination without parental consent [17]. Therefore, timely knowledge about the disease and the vaccine seems to be an important factor for vaccine program success.

From our study, knowledge is unrelated to other health concerns like cancer or traffic road accidents, or to other social concerns like terrorism. It seems that the way adolescents look at HPV is rather unusual and it is possibly because HPV is new in their lives and, although they might have heard about the virus, there is little concern about it.

The only factors independently associated with knowledge were not modifiable, being Spanish in origin and having an older sister vaccinated. Spanish girls do not have an easier access to vaccines, as vaccines are given for free to all subjects living in Spain, therefore the explanation that immigrant population know less about the disease is not due to a lack of contact with the health system or lower education, as we passed the questionnaires in schools. There are descriptions in the USA of Latin American girls being less vaccinated, and it is possibly due to cultural or traditional barriers rather than having less facilities [32].

Our girls perceive HPV vaccination as a vaccine for STD more than a vaccine to prevent cervical cancer, and this is partially expected by their adolescent condition. Their attitude towards the vaccine is more intuitive than reasoned, in an exercise that mix correct and incorrect knowledges.

This study has some limitations. A systematic review [33] concluded that differences among studies results might be partly explained by variations in the questionnaires and lack of validation or analysis of consistency. We piloted the questionnaire to validate comprehension, however it is possible that not all girls fully understood all questions. We included questions previously validated in other studies and found that the internal consistency of the constructs was high. 
Our response rate was not high, slightly over $65 \%$, but the recruitment was difficult as we needed to obtain an informed consent from mothers and informed assent from the girls, and the former were difficult. The head teachers had to contact parents through the girls. We were unable to assess whether the responders differed from the nonresponders, and that might have biased the results. School attendance is compulsory in Spain until the age of 16 therefore the universe of girls aimed for the questionnaire equaled the teenage population of Spain. In order to assess the representativity of our sample we compared our results with those of the National Institute of Statistics, and the distribution of our girls mirrored the general population in regards to the parent's job [34] as well as the origin of the family. With reference of the toxic consumption we compared our results with the last published national health survey (2011-2012) [35].

In this survey data from women 15 to 24 years of age is aggregated, tobacco consumption in this group was $20,95 \%$, slightly higher than our confidence interval. With regards to alcohol consumption, in the survey $20.5 \%$ of this group drank at least weekly, which is a lower figure that our sample's answer to regular consumption. From the vaccination point of view, our sample had slightly higher vaccination coverage than the official figure for at least one vaccine dose $(75 \%$ vs $66.5 \%)$. We considered that the sample was not very different to the general population as there was no a tendency to higher or lower toxic consumption, and also the age group we compared was not exactly the same. Therefore the fact that only $65 \%$ of the mothers signed the informed consent could bias the results but our estimation is that their representativity was high.

\section{Conclusion}

In conclusion, knowledge about HPV and it prevention is fair in Spanish adolescents, although they had important gaps. Their information is unrelated to the number contacts with the health system but to their discussions with peers, which might pose the vaccination program at risk in case of spurious associations.

Acceptability might increase if misleading information is explained and discussed with health providers that might devote a longer time to explain the disease and vaccine to adolescents. However this activity should be further evaluated.

\footnotetext{
Abbreviations

AIDS: Acquired immunodeficiency syndrome; CSISP: Center for public health research; GP: General practitioner; HIV: Human immunodeficiency virus; STD: Sexually transmitted diseases; USA: United States of America; HPV: Human papillomavirus.
}

\section{Competing interests}

Díez-Domingo and Puig-Barberá were principal investigators in clinical trials sponsored by GlaxoSmithKlein, Merk and Sanofi Pasteur MSD. The rest of authors have no conflict of interests.

This study was sponsored by Sanofi Pasteur - MSD.

\section{Authors' contributions}

PN and JD-D made substantial contributions to conception and design, acquisition of data, analysis and interpretation of data and writting the manuscript. EN, JP, JT and SA were involved in drafting the manuscript or revising it critically for important intellectual content. All of them have approved the manuscript to be published.

\section{Authors' information}

At the moment, all of the authors are working in vaccines research projects and public health.

PN is the Dean of the Faculty of Nursing in the Catholic University of Valencia. $J \mathrm{D}$ is the Research Director of the Vaccines Research Department in FISABIO, Valencian Government.

JT is the Director of the "Balmis" Chair of Vaccinology, in University of Alicante.

\section{Acknowledgements}

To Sanofi Pasteur - MSD, whose financial support has made this study possible. To every person who has contributed to the realization of this manuscript. As indicated in the authorship.

This manuscript has not been published in any journal. It has not been presented, in any way or form, in any national or international event.

\section{Author details}

'Facultad de Enfermería, Universidad Católica de Valencia "San Vicente Mártir", C/Jesús, 10, 46007 Valencia, Spain. Facultad de Medicina, Universidad Católica de Valencia "San Vicente Mártir", C/Quevedo, 2, 46001 Valencia, Spain. ${ }^{3} 3$ FISABIO (Fundación para el Fomento de la Investigación Sanitaria y Biomédica), Av/Cataluña, 21, 46020 Valencia, Spain. ${ }^{4}$ Cátedra Vacunología 'Balmis', UA-FISABIO, University of Alicante, Alicante, Spain.

Received: 5 November 2013 Accepted: 24 April 2014 Published: 22 May 2014

\section{References}

1. Muñoz N, Castellsagué X, de González AB, Gissmann L: HPV in the etiology of human cancer. Vaccine 2006, 24(Suppl 3):1-10.

2. International Agency Research for Cancer. World Health Organisation: Organisation: Spain (2012) Estimated Cancer Incidence, all Ages: Female. [http://globocan.iarcfr/old/summary_table_pop-html.asp?selection=183724\&title= Spain\&sex $=2 \&$ type $=0 \&$ window $=1 \&$ sort $=3 \&$ submit $=\% C 2 \% A 0$ Execute\%C2\%A0]

3. Miñarro R, Black R, Martínez C, Navarro C, Garau I, Izarzuguaza I, Arananaz E, Vergara A, Galceran J, Alonso R, Mateos A, Rodriguez M: Cancer Incidence and Mortality in Spain. Patterns and Trends. International Agency for Research on Cancer: Lyon; 2000.

4. Franco EL, Harper DM: Vaccination against human papillomavirus infection: a new paradigm in cervical cancer control. Vaccine 2005, 23:2388-2394

5. Harper D, Gall S, Naud P, Quint W: Substained immunogenicity and high efficacy against HPV-16/18 related cervical neoplasia: Long-term followup through 6,4 years in women vaccinated with Cervarix (GSK, s HPV 16/18 AS04 candidate vaccine). Gynecol Oncol 2008, 109:158-159.

6. Paavonen J, Naud P, Salmerón J, Wheeler CM, Chow SN, Apter D, Kitchener H, Castellsague X, Teixeira JC, Skinner SR, Hedrick J, Jaisamrarn U, Limson G, Garland S, Szarewski A, Romanowski B, Aoki FY, Schwarz TF, Poppe WA, Bosch FX, Jenkins D, Hardt K, Zahaf T, Descamps D, Struyf F, Lehtinen M, Dubin G, HPV PATRICIA Study Group: Efficacy of human papillomavirus (HPV) - 16/18 AS04-adjuvanted vaccine against cervical infection and precancer caused by oncogenic HPC types (PATRICIA): Final analysis of a doubled-blind, randomised study in young women. Lancet 2009, 374:301-314.

7. Joura E, Kjaer SK, Wheeler CM, Sigurdsson K, Iversen OE, Hernandez-Avila M, Perez G, Brown DR, Koutsky LA, Tay EH, García P, Ault KA, Garland SM, Leodolter S, Olsson SE, Tang GW, Ferris DG, Paavonen J, Lehtinen M, Steben M, Bosch X, Dillner J, Kurman RJ, Majewski S, Muñoz N, Myers ER, Villa LL, Taddeo FJ, Roberts C, Tadesse A, et al: HPV antibody levels and clinical efficacy following administration of a prophylactic quadrivalent HPV vaccine. Vaccine 2008, 26:6844-6851.

8. Joura EA, Leodolter S, Hernandez-Avila M, Wheeler CM, Perez G, Koutsky LA, Garland SM, Harper DM, Tang GW, Ferris DG, Steben M, Jones RW, Bryan J, Taddeo FJ, Bautista OM, Esser MT, Sings HL, Nelson M, Boslego JW, Sattler C, Barr E, Paavonen J: Efficacy of a quadrivalent prophylactic human 
papillomavirus (types 6, 11, 16, and 18) L1 virus-like-particle vaccine against high-grade vulval and vaginal lesions: a combined analysis of three randomised clinical trials. Lancet 2007, 369:1693-1702.

9. Tuells J, Duro Torrijos JL, Chilet Rosell E, Pastor Villalba E, Portero Alonso A, Navarro Ortiz C, Galiana de la Villa E: Noticias sobre el virus del papiloma humano y su vacuna en la prensa valenciana (2006-2011). Gac Sanit 2013, 27:374-377.

10. Martínez-González MA, Carlos S, de Irala J: Vacuna contra el virus del papiloma humano: razones para el optimismo y razones para la prudencia. Med Clin (Barc) 2008, 131:256-263.

11. Navarro-lllana P, Aznar J, Diez-Domingo J: Ethical considerations of universal vaccination against human papilloma virus. BMC Med Ethics, in press.

12. Gerend M, Shepherd J: Correlates of HPV knowledge in the era of HPV vaccination: a study of unvaccinated young adult women. Women Health 2011, 1:25-40

13. Keenan K, Hipwell A, Stepp S: Race and sexual behavior predict uptake of the human papillomavirus vaccine. Health Psychol 2012, 31:31-34.

14. Kessels SJM, Marshall HS, Watson M, Braunack-Mayer AJ, Reuzel R, Tooher RL: Factors associated with HPV vaccine uptake in teenage girls: a systematic review. Vaccine 2012, 30:3546-3556.

15. Fu LY, Bonhomme LA, Cooper SC, Joseph JG, Zimet GD: Educational interventions to increase HPV vaccination acceptance: A systematic review. Vaccine 2014, in press.

16. Kaufman J, Synnot A, Ryan R, Hill S, Horey D, Willis N, Lin V, Robinson P: Face to face interventions for informing or educating parents about early childhood vaccination. Cochrane Database Syst Rev 2013, (5): Art. No.: CD010038. doi:10.1002/14651858.CD010038.pub2.

17. Brabin L, Roberts SA, Kitchener HC: A semi-qualitative study of attitudes to vaccinating adolescents against human papillomavirus without parental consent. BMC Public Health 2007, 7:20

18. de Sanjose S, Cortés X, Méndez C, Puig-Tintore L, Torné A, Roura E, Bosch FX, Castellsague $X$ : Age at sexual initiation and number of sexual partners in the female Spanish population Results from the AFRODITA survey. Eur J Obstet Gynecol Reprod Biol 2008, 140:234-240.

19. Bowyer HL, Marlow LA, Hibbitts S, Pollock KG, Waller J: Knowledge and awareness of HPV and the HPV vaccine among young women in the first routinely vaccinated cohort in England. Vaccine 2013, 31:1051-1056.

20. Cabrera de León A, Rodríguez Pérez M, Domínguez Coello S: Validación del modelo REl para medir la clase social en población adulta. Rev Esp Salud Publica 2009, 83:231-242.

21. Jaworski B, Carey M: Development and psychometric evaluation of a self administered questionnaire to measure knowledge of sexually transmitted diseases. AIDS Behav 2007, 4:557-574.

22. Dempsey A, Cohn L, Dalton V, Ruffin M: Patient and clinic factors associated with adolescente hyman papillomavirus vaccine utilization within a university based health system. Vaccine 2010, 28:989-995.

23. Mortensen GL: Drivers and barriers to acceptance of humanpapillomavirus vaccination among young women: a qualitative and quantitative study. BMC Public Health 2010, 10:68.

24. Vadaparampil ST, Kahn JA, Salmon D, Lee JH, Quinn GP, Roetzheim R, Bruder K, Malo TL, Proveaux T, Zhao X, Halsey N, Giuliano AR: Missed clinical opportunities: provider recommendations por HPV vaccination for 11-12 year old girls are limited. Vaccine 2011, 47:8634-8641.

25. Bodemer N, Müller SM, Okan Y, Garcia-Retamero R, Neumeyer-Gromen A: Do the media provide transparent health information? A cross-cultural comparison of public information about the HPV. Vaccine 2012, 25:3747-3756.

26. Mathur M, Mathur $\mathrm{V}$, Reichling D: Participation in the decision to become vaccinated against human papillomavirus by California High School girls and the predictors of vaccine status. J Pediatr Health Care 2010, 24:14-24

27. Agius PA, Pitts MK, Smith AM, Mitchell A: Human Papillomavirus and cervical cancer: Gardasil vaccination status and knowledge amongst a nationally representative sample of Australian secondary school students. Vaccine 2010, 27:4416-4422.

28. Caskey R, Lindau S, Alexander G: Knowledge and early adoption of the HPV vaccine among girls and young women: results of a national survey. J Adol Health 2009, 45:453-462.

29. Wegwartha O, Kurzenhäuser-Carstens S, Gigerenzera G: Overcoming the knowledge-behavior gap: the effect of evidence-based HPV vaccination leaflets on understanding, intention, and actual vaccination decision. Vaccine 2014, 32:1388-1393.
30. Noakes K, Yarwood J, Salisbury D: Parental response to the introduction of a vaccine against human papilloma virus. Hum Vaccin 2006, 2:243-248.

31. Javitt G, Berkowitz D, Gostin L: Assessing mandatory HPV vaccination: who should call the shots? J Law Med Ethics 2008, 2:384-395.

32. Chando S, Tiro JA, Harris TR, Kobrin S, Breen N: Effects of socioeconomic status and health care access on low levels of human papillomavirus vaccination among Spanish-speaking Hispanics in California. Am J Public Health 2013, 2:270-272.

33. Allena JD, Coronado GD, Williams RS, Glenn B, Escoffery C, Fernandez M, Tuff RA, Wilson KM, Mullen PD: A systematic review of measures used in studies of human papillomavirus (HPV) vaccine acceptability. vaccine 2010, 28:4027-4037.

34. Instituto Nacional de Estadística: INEbase, Indicadores Sociales, Edición 2011. [http://www.ine.es/daco/daco42/sociales11/sociales.htm]

35. Instituto Nacional de Estadística: Encuesta de Salud 2013. [http://www.ine es/jaxi/menu.do;jsessionid=E35B0D01B1416C7691485D1448FE740A.jaxi03? type $=$ pcaxis\&path $=/$ t15/p419\&file=inebase\&L=0]

doi:10.1186/1471-2458-14-490

Cite this article as: Navarro-Illana et al:: "Knowledge and attitudes of Spanish adolescent girls towards human papillomavirus infection: where to intervene to improve vaccination coverage". BMC Public Health 2014 14:490.

\section{Submit your next manuscript to BioMed Central and take full advantage of:}

- Convenient online submission

- Thorough peer review

- No space constraints or color figure charges

- Immediate publication on acceptance

- Inclusion in PubMed, CAS, Scopus and Google Scholar

- Research which is freely available for redistribution 